\title{
Patients with skin disease and their relationships with their doctors: a qualitative study of patients with acne, psoriasis and eczema
}

\author{
Parker J Magin, Jon Adams, Gaynor S Heading and C Dimity Pond
}

S kin diseases are common, with $16 \%$ of Australian general practice consultations containing a dermatological element. ${ }^{1}$ Among the most common skin diseases are acne ("one of the commonest diseases known to humanity"), ${ }^{2}$ eczema (which affects $9.7 \%$ of 13-14-year-olds in Australia) $)^{3}$ and psoriasis (which has a community prevalence of $0.3 \%-2.5 \%){ }^{4}$

The morbidity of skin disease can be considerable, with abundant evidence of psychological morbidity, ${ }^{5}$ impaired quality of life, ${ }^{6}$ and suicidal ideation. ${ }^{7}$ There is also evidence that patients with skin disease feel that their doctors trivialise their condition, underestimate its impact, and fail to adequately appreciate its psychological aspects. $^{8-13}$ Empirical research supports these perceptions - in an Australian study, only $3.4 \%$ of dermatologists nominated psychological factors as an important criterion for assessing eczema severity. ${ }^{14}$

Research in this area is largely quantitative. However, as it concerns attitudes and "lived experiences", the topic is well suited to qualitative methodology. We conducted a qualitative study to explore the experiences of patients with skin disease in their relationships with their treating doctors.

\section{METHODS}

Recruitment was via mailed invitations to participants of an earlier, quantitative phase of the project ${ }^{15}$ (patients with skin disease recruited by six urban dermatologists and 26 general practitioners), and invitations to participate were posted in these GPs' waiting rooms. Recruitment reflected sampling based on severity of skin disease, care by GP or dermatologist, age and sex.

In-depth, semi-structured interviews were conducted between January 2004 and April 2005 by a single researcher (PJM), a GP. Interviews were recorded and transcribed verbatim. Data collection continued until thematic saturation was achieved.

We used the analytic induction method for data analysis, which allows ideas and themes to emerge from the data. ${ }^{16}$ Addi-

\section{ABSTRACT}

Objective: To explore the experiences of patients with acne, psoriasis or atopic eczema in their relationships with their treating doctors.

Design: Qualitative study, using semi-structured interviews conducted between January 2004 and April 2005, thematic analysis and modified grounded theory methodology.

Setting and participants: Participants were patients with acne, psoriasis or atopic eczema recruited from urban general practices and urban dermatology practices.

Results: 62 semi-structured interviews were conducted. Reports of negative experiences with doctors treating participants' skin conditions were common. Both general practitioners and dermatologists were reported as having poor comprehension of the psychological implications of skin diseases, being insensitive to their patients' emotional suffering, and trivialising participants' disease. Participants acknowledged that time considerations and other pressures may explain these apparent deficiencies. Some participants perceived their doctors as medical technicians and sought treatment for their physical skin disease, not for its emotional or social aspects.

Conclusion: We recommend education for GPs about the psychological effects of skin diseases, and education for dermatologists and GPs on how to elicit and manage, or appropriately refer, these problems.

MJA 2009; 190: 62-64

tional topics for exploration were added as new areas of interest emerged, and negative cases were sought.

Data analysis was cumulative and concurrent throughout the data collection period, reflecting modified grounded theory. ${ }^{17}$ Each transcript was separately coded by two members of the research team (PJM and GSH), and comparative coding was conducted.

The study received ethics approval from the University of Newcastle Human Research Ethics Committee.

\section{RESULTS}

We interviewed 62 patients with acne (26), psoriasis (29) or atopic eczema (7). Twentyfive participants were male and 37 were female; they ranged in age from 13 to 73 years.

\section{Relationships with GPs}

Relationships between participants and their doctors were complex. Participants felt that GPs' expertise regarding skin disease was very variable.
Participants reported that GPs were sometimes dismissive of the significance of their disease. Participants also felt that this attitude reflected either the GPs' lack of expertise and interest in the area, or a lack of appreciation of the psychological import of skin disease:

I don't think the doctors have any idea of the torture that we go through ... I just don't think that the doctors pay enough attention to the skin problems and the effects that they have on patients. (Woman with eczema, 33 years)

For at least some participants, GPs' pejorative or unsympathetic attitudes contributed to feelings of guilt or decreased self-esteem:

[The GP said] "Oh, well the last patient that came in here had cancer". So you have a skin disease? So it's really not that important. You should just put some cream on it and get over it. (Woman with eczema, 19 years)

The lack of empathy and lack of patientcentred approach felt to be present in participants' relationships with doctors is typified by the following response: 
I had one doctor who did have it when he was young, he had acne scars and that. He was [a] bit more sympathetic but there were ones that didn't. To be honest, some of the GPs they just wrote the script out and "Off! On your way." (Man with acne, 24 years)

The implications of this lack of patientcentredness are illustrated by the capacity of doctors with an empathetic attitude to positively influence patient care:

If you find a doctor that you can really get on with, that you have a rapport with, it's terrific. If you've got a doctor that you can't, and there are many around, it just doesn't seem to matter what they try to do or what you try to do, nothing works. (Woman with psoriasis, 56 years)

Not all negative experiences with GPs, however, were seen as necessarily being a failing on the doctor's part. Patients appreciated the intrinsically difficult nature of skin disease management:

I don't think it's really [my GP's] fault or anything. It's just that I don't think people generally understand the effects [of psoriasis]. (Woman with psoriasis, 42 years)

The demands on GPs and their responsibilities to other patients were appreciated by some participants. The fact that skin diseases are generally not life-threatening was a key factor. One participant understood the process that led to her GP trivialising her disease:

I think that in comparison with people who have life-threatening problems that go in there [to the GP], that [my psoriasis] is pretty trivial. He's very booked up, he's very overworked and overstressed himself, so something like that, to me would appear trivial, you know. (Woman with psoriasis, 31 years)

A further perspective was that patients may not have been seeking psychological management. These patients sought physical solutions to what they perceived to be a physical problem:

Probably, you are looking for a cure, that's what you are looking for. You don't want sympathy, you want a cure. (Man with psoriasis, 53 years)

\section{Relationships with dermatologists}

Participants rated dermatologists highly for technical expertise. Some had experienced positive encounters with dermatologists who had empathetic approaches. But many felt that dermatologists were uninterested in the psychological burden of their disease:

The experiences I've had with dermatologists so far is that ... they certainly don't understand the emotional effects of psoriasis. (Woman with psoriasis, 43 years)

Again, for some patients this was not necessarily a failing — the dermatologist was a technician whose job it was to treat the physical, not the psychological, manifestations of their disease:

[My dermatologist] wasn't particularly sympathetic but, then, it isn't their job to be. (Woman with eczema, 21 years)

\section{DISCUSSION}

This study reveals complexity in the relationships between doctors and patients with skin disease. Congruent with previous quantitative research, ${ }^{8,10}$ patients were dissatisfied with their doctors' empathy and appreciation of the extent of their suffering.

The implications of these findings may be considerable. An Italian study found that dermatologists' interpersonal skills and empathetic approach were the most important factors in patient satisfaction with management, ${ }^{18}$ and led to improved treatment compliance. ${ }^{19}$ Similarly, Swedish patients with psoriasis place greater emphasis on being treated politely than on being cured. ${ }^{20}$ In our study, an empathetic practitioner was felt to have reduced psychological sequelae in some patients - an outcome proposed elsewhere ${ }^{19,21,22}$ but not previously documented.

Our study's qualitative methodology elicited complexities in relationships between doctors and patients with skin disease not apparent in previous studies. Important among these was the appreciation by some participants that time considerations and other pressures may explain the apparent failings of practitioners.

Our finding that some patients felt that their doctor was a medical technician whose role was to physically treat their skin disease, and that the psychological implications were not within the doctor's remit, is consistent with the result of a New Zealand study that $37 \%$ of general practice patients with psychiatric symptoms had not disclosed them to their GP. ${ }^{23}$ Cited reasons included a perception that a GP is not an appropriate person to talk to, or that mental health issues should not be discussed, the stigma of mental illness, and systems factors such as time pressures in the consultation. ${ }^{23}$ These factors were operating in our study; some participants did not recognise their GP as a source of psychological support or management.

An unexplored area is how stigmatisation of mental illness might be especially problematic in the setting of skin disease, which is already associated with considerable stigma. This may be accentuated by the perceived trivialisation of skin disease seen in our study and reported elsewhere. ${ }^{8}$ Patients with skin disease may be even more reluctant to present psychological symptoms to their GP given these perceptions. This topic deserves further research.

The complexity of clinical scenarios and the constraints upon clinicians should be acknowledged. But, despite these caveats, our results suggest that there is appreciable mismatch of patients' and doctors' perceptions and expectations during consultations for skin diseases. We recommend education for GPs about the potential psychological effects of skin diseases, and for dermatologists and GPs about the means to elicit and manage, or appropriately refer, these problems.

\section{COMPETING INTERESTS}

None identified.

\section{AUTHOR DETAILS}

Parker J Magin, PhD, DPD, FRACGP, Senior Lecturer $^{1}$

Jon Adams, MA, PhD, Head ${ }^{2}$

Gaynor S Heading, BA, GradDipHSS(MSS), PhD, Honorary Associate Professor ${ }^{3}$

C Dimity Pond, MB BS, PhD, FRACGP, Head ${ }^{1}$

1 Discipline of General Practice, University of Newcastle, Newcastle, NSW.

2 Discipline of Social Science, School of Population Health, University of Queensland, Brisbane, QLD.

3 University of Sydney, Sydney, NSW.

Correspondence:

parker.magin@newcastle.edu.au

\section{REFERENCES}

1 Britt H, Miller GC, Knox S, et al. General practice activity in Australia 2001-2002. Canberra: Australian Institute of Health and Welfare, 2002: 32-40. (AIHW Cat. No. GEP 10.)

2 Chan J, Rohr J. Acne vulgaris: yesterday, today and tomorrow. Australas J Dermatol 2000; 41 Suppl: S69-S72.

3 Robertson CF, Dalton MF, Peat JK, et al. Asthma and other atopic diseases in Australian children. Australian arm of the International Study of Asthma and Allergy in Childhood. Med J Aust 1998; 168: 434-438. 


\section{HEALTH CARE}

4 Plunkett A, Marks R. A review of the epidemiology of psoriasis vulgaris in the community. Australas J Dermatol 1998; 39: 225-232.

5 Gupta MA, Gupta AK. Psychiatric and psychological co-morbidity in patients with dermatologic disorders: epidemiology and management. Am J Clin Dermatol 2003; 4: 833-842.

6 Halioua B, Beumont MG, Lunel F. Quality of life in dermatology. Int J Dermatol 2000; 39: 801806.

7 Gupta MA, Gupta AK. Depression and suicidal ideation in dermatology patients with acne, alopecia areata, atopic dermatitis and psoriasis. Br J Dermatol 1998; 139: 846-850.

8 Jowett S, Ryan T. Dermatology patients and their doctors. Clin Exp Dermatol 1985; 10: 246254.

9 Porter JR, Beuf AH, Lerner A, Nordlund J. Psychosocial effect of vitiligo: a comparison of vitiligo patients with "normal" control subjects, with psoriasis patients, and with patients with other pigmentary disorders. J Am Acad Dermatol 1986; 15: 220-224.

10 Long CC, Funnell CM, Collard R, Finlay AY. What do members of the National Eczema Society really want? Clin Exp Dermatol 1993; 18: 516-22.
11 Koo J. Population-based epidemiologic study of psoriasis with emphasis on quality of life assessment. Dermatol Clin 1996; 14: 485-496.

12 National Psoriasis Foundation. Benchmark survey on psoriasis and psoriatic arthritis: summary of top-line results. Portland, Ore: NPF, 2001. http://www.psoriasis.org/files/pdfs/press/ 2001 benchmarksurvey.pdf?PHPSESSID = 7 bcd 18 a 54 a a 6ce 17 d 2968 ba ce 920087 e (accessed Oct 2008).

13 Jobling RG. Psoriasis - a preliminary questionnaire study of sufferers' subjective experience. Clin Exp Dermatol 1976; 1: 233-236.

14 Stephens RB, Cooper A. The caseload, assessment and treatment of atopic dermatitis: a survey of Australian dermatologists. Australas J Dermatol 1999; 40: 187-189.

15 Magin P, Pond D, Smith W, et al. A crosssectional study of psychological morbidity in patients with acne, psoriasis and atopic dermatitis in specialist dermatology and general practices. J Eur Acad Dermatol Venereol 2008; 26 Jun [Epub ahead of print].

16 Pope C, Ziebland S, Mays N. Analysing qualitative data. BMJ 2000; 320: 114-116.

17 Bogdan RC, Biklen SK. Qualitative research for education: an introduction to theories and methods. Boston: Allyn \& Bacon, 1998.
18 Renzi C, Abeni D, Picardi A, et al. Factors associated with patient satisfaction with care among dermatological outpatients. $\mathrm{Br} J$ Dermatol 2001; 145: 617-623.

19 Renzi C, Picardi A, Abeni D, et al. Association of dissatisfaction with care and psychiatric morbidity with poor treatment compliance. Arch Dermatol 2002; 138: 337-342.

20 Uttjek M, Dufaker M, Nygren L, Stenberg B. Psoriasis care consumption and expectations from a gender perspective in a psoriasis population in northern Sweden. Acta Derm Venereol 2005; 85: 503-508.

21 Feldman S, Behnam SM, Behnam SE, Koo JY. Involving the patient: impact of inflammatory skin disease and patient-focused care. J Am Acad Dermatol 2005; 53 (1 Suppl 1): S78-S85.

22 Lamb CA, Fried RG, Feldman SR. Giving patients "perceived control" over psoriasis: advice for optimizing the physician-patient relationship. J Dermatolog Treat 2004; 15: 182184.

23 Bushnell J, McLeod D, Dowell A, et al. Do patients want to disclose psychological problems to GPs? Fam Pract 2005; 22: 631-637.

(Received 13 Apr 2008, accepted 25 Jun 2008) 